\title{
JOHN RAWLS E AMARTYA SEN: PARALELO ENTRE A TEORIA DE JUSTIÇA COMO EQUIDADE E A JUSTIÇA FOCADA NAS REALIZAÇÕES
}

\author{
Heloisa Sami Daou ${ }^{1}$ \\ José Claudio Monteiro de Brito Filho
}

\section{RESUMO}

O presente artigo visa a apresentar e a comparar duas distintas teorias da justiça, a teoria da justiça como equidade de John Rawls e a teoria da justiça focada nas realizações de Amartya Sen, de modo a destacar suas afinidades e divergências. Inicialmente, apresenta-se a teoria de Rawls, mais especificamente delineada na obra Uma Teoria da Justiça. Em seguida, aborda-se a concepção de Sen em relação à justiça social centrada em realizações. E, por fim, são apresentadas as críticas de Sen a Rawls em uma abordagem comparativa entre as teorias.

Palavras-Chave: John Rawls; Justiça como equidade; Amartya Sen; Justiça focada em realizações; Teorias da Justiça.

\section{JOHN RAWLS AND AMARTYA SEN: PARALLEL BETWEEN THE THEORY OF JUSTICE AS EQUITY AND JUSTICE FOCUSED ON ACHIEVEMENTS}

\begin{abstract}
The present article aims to present and compare two different theories of justice, John Rawls' theory of Justice as fairness, and Amartya Sen's theory of justice focused on the achievements, in order to highlight their affinities and divergences. Initially, it is present the theory of Rawls, more specifically outlined in the book A Theory of Justice. Then, it is approach Sen's conception of achievement-centered social justice. And, finally, it is stand out from Sen's criticisms of Rawls in a comparative approach between theories.
\end{abstract}

Keywords: John Rawls; Justice as fairness; Amartya Sen; Justice focused on the achievements; Theories of Justice.

\section{INTRODUÇÃO}

John Rawls é um marco na história da filosofia política, tanto que não é exagerada a afirmação de que a concepção contemporânea de justiça distributiva se firma a partir da teoria de justiça por ele desenvolvida na obra Uma Teoria da Justiça, lançada em 1971.

Rawls reacendeu o debate sobre o ideal e os fundamentos de uma sociedade justa, ao propor uma concepção de justiça chamada Justiça como Equidade e revigorou a teoria tradicional do contrato social, apresentada por Lock, Rousseau e Kant. Nos anos seguintes à publicação da obra de Rawls, sua teoria foi objeto de inúmeros debates intelectuais, passando

\footnotetext{
1 *Mestranda do programa de Pós-Graduação stricto sensu do Centro Universitário do Estado do Pará CESUPA. E-mail: helo_daou@yahoo.com.br

2 *Doutor em Direito das Relações Sociais pela PUC/SP. Professor dos Programas de Pós-Graduação em Direito da UFPA e do CESUPA. E-mail: jclaudiobritofilho@gmail.com
} 
a ser referência obrigatória para os teóricos políticos que, em suas teorias, comentam as ideias rawlsianas, como, por exemplo, Robert Nozick e Michael Sandel.

Contudo, a melhor forma de distribuir direitos e liberdades em uma sociedade continua sendo uma questão polêmica e de difícil resposta na filosofia política, isso porque o debate pode suscitar diversas concepções de justiça distributiva, todas elas, cada uma ao seu modo, buscando soluções para as diversas formas de desigualdades.

Nesse sentido, a teoria da justiça como equidade, como toda teoria da justiça, busca alternativas para uma melhor distribuição de bens e riquezas na sociedade. Rawls não se exime de responder três perguntas básicas a todo teórico da justiça distributiva: o que distribuir? A quem? De que forma? Assim, a teoria de Justiça como Equidade de Rawls instigou o debate entre as mais variadas linhas de pensamento, o que em muito contribuiu para o tema da justiça social.

Amartya Sen destaca-se, nesse contexto, como grande pensador contemporâneo que participa do diálogo com Rawls. Sua contribuição consolidou-se com a publicação, em 2009, da obra A ideia de Justiça. Não há um consenso sobre como o pensamento de Sen pode ser classificado em relação à filosofia política, especialmente porque o próprio autor não se posiciona claramente. Entretanto, as linhas desenvolvidas na obra anteriormente citada, bem como nas obras posteriores Desenvolvimento como Liberdade (2010) e Desigualdade Reexaminada (2012) acabam por aproximar o economista indiano às concepções de Justiça Distributiva no contexto do liberalismo de princípios.

Sen julga que o Iluminismo produziu duas principais linhas de argumentação racional sobre a justiça, quais sejam: o institucionalismo transcendental e a abordagem da comparação focada em realizações. Para o autor, o institucionalismo transcendental foi uma abordagem iniciada com Thomas Hobbes no século XVII, acompanhada pelos demais contratualistas, tais como John Locke, Jean-Jacques Rousseau, Immanuel Kant e John Rawls. A característica marcante dessa abordagem é a tentativa de encontrar arranjos institucionais que sejam justos para a realidade social. Nessa esteira, objetiva-se caracterizar o que seria uma sociedade justa ao invés de desenvolver critérios para identificar que uma determinada alternativa pode ser menos injusta que a outra (SEN, 2011, 35-36).

Por sua vez, a abordagem focada nas realizações é encontrada nas produções de filósofos como Adam Smith, Jeremy Bentham, Karl Marx e John Stuart Mill. Nessa abordagem, a metodologia empregada é a análise comparativa focada nas realizações sociais, 


\section{JOHN RAWLS E AMARTYA SEN: PARALELO ENTRE A TEORIA DE JUSTIÇA COMO EQUIDADE E A JUSTIÇA FOCADA NAS REALIZAÇÕES}

com vistas à remoção das injustiças evidentes do mundo em que seus idealizadores eram partícipes. Essa perspectiva defende que a injustiça pode estar ligada a transgressões comportamentais e não a defeitos institucionais.

Sen compreende que a maioria das teorias de justiça contemporâneas está baseada na abordagem institucional transcendental, inclusive a teoria de Rawls. Contudo, deixa claro que a sua investigação está ligada à abordagem da comparação focada nas realizações, afirmando que, em contraste com a maioria das teorias de justiça modernas, que se concentram na 'sociedade justa', sua obra "é uma tentativa de investigar comparações baseadas nas realizações que focam o avanço ou retrocesso da justiça" (SEN, 2011, p. 39).

Assim, para Sen, enquanto uma teoria da justiça de abordagem transcendental pretende responder a pergunta "o que seriam as instituições perfeitamente justas?”; a abordagem de comparação focada em reaplicações, ao seu turno, quer encontrar resposta para a pergunta de “como a justiça pode ser promovida?”. Pelo que se vê, a diferença principal está na abordagem. Mas, apesar disso, a busca pela argumentação racional no debate público, segundo Sen, são importantes pontos em comum.

Logo, embora Sen formule críticas a Rawls, ambos dedicam-se à elaboração de concepções de justiça de cunho igualitarista e procuram lidar com as questões de desigualdades e pobrezas nas sociedades democráticas contemporâneas. Ademais, ambos rejeitam posições utilitaristas. Por isso, na visão de Vita (1999, p. 1), a divergência entre os autores pode ser entendida como uma "briga em família".

Inicialmente, apresentar-se-á a teoria da justiça como equidade de Rawls, mais especificamente delineada na obra Uma Teoria da Justiça; em seguida, será abordada a concepção de Sen em relação à justiça social centrada em realizações. E, por fim, destacar-seão as críticas de Sen a Rawls em uma abordagem comparativa entre as teorias.

O presente ensaio é uma obra de hermenêutica, ancorada na análise qualitativa e, para atingir os objetivos elencados, a metodologia empregada foi a revisão bibliográfica de livros e artigos científicos sobre o tema.

\section{A JUSTIÇA COMO EQUIDADE DE JOHN RAWLS}

John Rawls inaugurou uma nova forma de se conceberem os deveres e o papel do Estado para com a sociedade. Ele mantém o respeito pela autonomia individual, mas 
considera que o Estado não pode se escusar de garantir a todos os indivíduos e a estes isoladamente uma gama de bens primários, necessários à consecução de qualquer projeto de vida. Para ele, "tratar casos semelhantes de maneira semelhante não é garantia suficiente de justiça substantiva" (RAWLS, 2016, p.71). Assim, a função do Estado tem início e fim na garantia do básico, a partir de quando deve ser neutro.

A teoria de Rawls é deontológica, o que implica dizer que o justo prevalece sobre o bem. Nessa abordagem, Rawls retoma Kant, para quem a noção de justiça considera cada pessoa como um fim em si mesma e não como meio que pode ser colocado em sacrifício para o bem da maioria. Contudo, Rawls vai além de Kant, trazendo para o debate a dimensão institucional da justiça, sustentada a partir da noção de justiça como atributo central para a cooperação social e que faz referência à estrutura básica da sociedade. Ele assinala que

a justiça é a primeira virtude das instituições sociais (...) cada pessoa possui uma inviolabilidade fundada na justiça que nem o bem-estar de toda a sociedade não pode desconsiderar. Por isso, a justiça nega que a perda de liberdade de alguns se justifique por um bem maior desfrutado por outros. Não permite que os sacrifícios impostos a poucos sejam contrabalanceados pelo número maior de vantagens de que desfrutam muitos. Por conseguinte, na sociedade justa as liberdades da cidadania igual são consideradas irrevogáveis; os direitos garantidos pela justiça não estão sujeitos a negociações políticas nem ao cálculo de interesses pessoais." (RAWLS, 2016, p.04)

Para Rawls a justiça de uma sociedade mostra-se na igualdade entre os seres humanos como valor intrínseco. Assim, todo o suporte necessário - direitos, oportunidades, liberdades e recursos sociais - para que cada um possa desenvolver a vida de acordo com suas próprias convicções morais deve ser oferecido pelas instituições básicas.

Ademais, Rawls é um contratualista, tradição que considera a constituição política e as leis como justas somente quando acordadas por pessoas racionais e livres, com direitos iguais e com igual autoridade política. Nesse sentido:

A natureza hipotética do acordo de Rawls na posição original se parece a ideia do contrato original de Kant, do qual Kant disse que é um contrato social hipotético e não real. Na leitura de Rawls todos os proponentes principais da tradição do contrato social, desde Hobbes, através de Locke e Rousseau, até Kant, consideram o contrato social como um experimento de pensamento hipotético que está desenhado para mostrar quais são os termos mais razoáveis de cooperação entre pessoas racionais que são consideradas iguais (FREEMAN, 2016, p. 35) ${ }^{3}$.

\footnotetext{
${ }^{3}$ No original: La naturaleza hipotética del acuerdo de Rawls en la posición original se parece a la ideia del contrato original de Kant, del cual Kant dice que es un contrato social hipotético y no real. En la lectura de Rawls todos los proponentes principales de la tradición del contrato social como un experimento de pensamiento
} 


\section{JOHN RAWLS E AMARTYA SEN: PARALELO ENTRE A TEORIA DE JUSTIÇA COMO EQUIDADE E A JUSTIÇA FOCADA NAS REALIZAÇÕES}

Duas ideias que são fundamentais na teoria rawlsiana: a sociedade como um sistema de cooperação e a estrutura básica da sociedade. Primeiramente, a cooperação social é elemento indispensável na sociedade bem ordenada. É dizer: os seus integrantes, cada um com seus respectivos talentos, devem interagir a fim de criar um ambiente social melhor para todos, por entenderem que isso incrementa tanto a situação da sociedade como a sua própria, mais do que se agissem cada um por si. E, a partir desta compreensão, todos estariam dispostos a seguir as regras que ordenam a união societária.

Ao mesmo tempo em que a sociedade é marcada pelo conflito de interesses, sua unidade baseia-se na aceitação, por parte dos cidadãos, de uma concepção política da justiça que faz uso de ideias do bem, consideradas razoáveis (ou seja, compatíveis com essa concepção política da justiça) e que compartilham a mesma concepção de pessoa, o que garante que os princípios da justiça sejam aplicados, além de assegurar a estabilidade social.

No que diz respeito à estrutura básica da sociedade, Rawls (2016, p. 9) afirma que a justiça de um arranjo social depende, em essência, “de como se atribuem os direitos e deveres fundamentais e também das oportunidades econômicas e das condições sociais dos diversos setores da sociedade". Assim, a finalidade primeira da teoria consiste em formular uma concepção de justiça cujos princípios sejam a baliza de tratamento para as questões clássicas relacionadas somente a um contexto específico: a estrutura básica.

Para Rawls, em uma sociedade bem ordenada, os arranjos sociais são justos a partir do conceito de justiça procedimental pura, ou seja, não importa o resultado quando o método é justo, porquanto aceito previamente por todos. Nesta sociedade, os indivíduos confiam nas instituições, pois elas lhes proporcionam confiança do seu próprio valor e de que os seus planos terão chances exitosas; estes agirão de maneira justa desde que seus atos estejam em conformidade com as exigências destas instituições.

$\mathrm{Na}$ medida em que isso tudo é verdadeiro, Rawls (2016, p. 562) afirma que "uma concepção de justiça é psicologicamente adequada às inclinações humanas". E, ainda, "se o desejo de agir com justiça também for regulador de um projeto de vida racional, agir com

hipotético que está diseñado para mostrar cuáles son los términos más razonables de coorperación entre personas racionales que son consideradas iguales (FREEMAN, 2016, p. 35).

Rev. de Teorias da Justiça, da Decisão e da Argumentação Jurídica | e-ISSN: 2525-9644| Maranhão | v. 3 | n. 2 | p. 1 - 21| Jul/Dez. 2017. 
justiça faz parte do nosso bem" (RAWLS, 2016, p. 562), demonstrando que, nesse caso, o bem e o justo são compatíveis e o todo é congruente.

Assim, é fundamental perceber que Rawls reconhece a ligação entre o justo e o bem, como dois conceitos fundamentais, mas se afasta das teorias teleológicas como ideais de ligação desses conceitos, especialmente pelo fato de essas teorias definirem o bem de maneira independente do justo. Ao contrário, Rawls insere uma teoria do bem em sua obra, mas reafirma o caráter deontológico do seu projeto, pois a justiça na teoria do autor parece ir além da mera preocupação com interesses circunstanciais. A preocupação é com uma concepção geral de bem, ou seja, proporcionar o básico a todos e permitir a liberdade do cidadão para perseguir seu próprio plano de vida boa.

$\mathrm{Na}$ teoria rawlsiana, a escolha de bens primários, entendidos como bens que todos escolheriam, antecede a escolha dos princípios da justiça, vez que são bens necessários para esta escolha. E a concepção de cada indivíduo sobre o bem próprio se adapta aos princípios de justiça. Os bens primários são definidos como coisas que sempre seria melhor ter mais do que menos, ou, em outras palavras, coisas que todo homem racional deseja mais que outras ou deseja ainda que deseje outras. Desse modo, esclarece Kymlicka (2006, p. 83):

Estamos todos comprometidos com um ideal de boa vida e certas coisas são necessárias para perseguir estes compromissos, seja qual for seu conteúdo mais específico. Segundo a teoria de Rawls, estas coisas são chamadas de "bens primários". Há dois tipos de bens primários:

1. bens primários sociais - bens que são diretamente distribuídos pelas instituições sociais, como renda e riqueza, oportunidades e poderes, direitos e liberdades;

2. bens primários naturais - bens como saúde, a inteligência, o vigor, a imaginação e os talentos naturais, que são afetados pelas instituições sociais, mas não são diretamente distribuídos por elas.

Nesse sentido, importante destacar que os bens primários a que Rawls se refere são os sociais, pois possuem estreita relação com a estrutura básica da sociedade, conforme destaca Brito Filho (2015, p. 60):

Os bens primários a que Rawls se refere, a propósito, são os bens primários sociais, e que, como explica Kymlicka, constituem os distribuídos pelas instituições sociais, e não os naturais, como a saúde e os talentos, entre outros, e que, embora possam ser influenciados de diversas formas pelas instituições sociais, não são por elas distribuídos.

Assim, pode-se resumir a lista de Rawls falando de autoestima ou autorrespeito, direitos, liberdade e oportunidades, bem como renda e riqueza (RAWLS, 2016, p. 110). 


\section{JOHN RAWLS E AMARTYA SEN: PARALELO ENTRE A TEORIA DE JUSTIÇA COMO EQUIDADE E A JUSTIÇA FOCADA NAS REALIZAÇÕES}

Mesmo em uma teoria deontológica não é possível prescindir desses bens, uma vez que eles não se relacionam às particularidades, mas são bens gerais, necessários para o sucesso de qualquer plano de vida, diretamente relacionados à dignidade da pessoa humana. Logo, não se justifica a prioridade do justo impondo uma doutrina particular.

Mas, as pessoas são diferentes, têm desejos diferentes e manifestam necessidades as mais variadas possíveis. Porém, a alegação de Rawls é de que:

para alguns bens, não importando qual seja o seu plano de vida, acontecerá simplesmente que sempre será racional você querer mais, e não menos, desses bens (LOVETT, 2013, pg. 62-63).

Ou seja, mesmo diante de tantas diferenças, há bens que todos escolheriam em uma posição original, embora cobertos pelo véu da ignorância, sem conhecimentos sobre o futuro, em que as escolhas são feitas com base em fatos gerais e as pessoas não conhecem sequer a noção de próprio bem, esses bens são imprescindíveis. Gargarella (2008, pg. 23) reforça, afirmando que:

Os "bens primários" seriam aqueles bens básicos indispensáveis para satisfazer qualquer plano de vida. (...). A idéia, nesse caso, corresponde a princípios claramente não perfeccionistas: qualquer pessoa precisa estar em condições de buscar seu próprio projeto de vida, independentemente - em princípio - do conteúdo dele.

Rawls observa que, em circunstâncias normais, as pessoas preferem liberdades e oportunidades mais amplas às mais restritas e uma parcela maior, e não menor, de riqueza e renda. Parece bem claro que estas coisas são boas. Mas, também acrescenta à sua lista o autorrespeito ou a confiança na noção do próprio valor, que defenderá adiante como sendo o mais importante bem primário. Para Rawls, pode-se compreender o autorrespeito ou a autoestima em dois aspectos:

Em primeiro lugar, (...), essa idéia contém o sentido que a pessoa tem de seu próprio valor, sua firme convicção de que vale a pena realizar sua concepção de bem, seu projeto de vida. E, em segundo lugar, o auto-respeito implica uma confiança na própria capacidade contanto que isso esteja ao alcance da pessoa, de realizar suas próprias intenções. (...). Sem ele, parece que não vale a pena fazer nada, ou, se alguma coisa tem valor para nós, falta-nos disposição para luta por ela (RAWLS, 2016, p. 544).

Com uma quantidade maior de bens primários Rawls conclui que “(...), em geral é possível prever um maior êxito na realização das próprias intenções e na promoção dos próprios objetivos, sejam quais forem esses objetivos.” (RAWLS, 2016, p. 110). Assim, as

Rev. de Teorias da Justiça, da Decisão e da Argumentação Jurídica | e-ISSN: 2525-9644| Maranhão | v. 3 | n. 2 | p. 1 - 21| Jul/Dez. 2017. 
pessoas podem desejar outros bens (que não os primários), de acordo com aquilo que julgam melhor, bem como a importância do bem primário em relação a esses outros bens pode variar. Porém, mesmo que os objetivos das pessoas sejam diametralmente opostos, os bens primários sempre serão essenciais, por isso escolhidos antes mesmo dos princípios da justiça.

A sociedade de Rawls é presumidamente bem ordenada e ele denomina a situação inicial de posição original, hipoteticamente, a situação na qual os membros da sociedade decidem, em que são escolhidos os princípios de justiça e os indivíduos estão cobertos pelo "véu" da ignorância. Significa dizer que os cidadãos que participam da formulação desses princípios não possuem informações nem sobre suas condições sociais, nem sobre a de outros, o que também garante que determinadas concepções individuais do bem não tenham influência sobre a escolha dos princípios.

Esses princípios regularão a estrutura básica da sociedade e cuidam, tão somente, da distribuição dos bens primários, reitera-se, aqueles que "se presume que um indivíduo racional deseje, não importando o que mais ele deseje" (RAWLS, 2016, p. 110). Nesse sentido, os dois princípios de justiça são formulados da seguinte maneira:

Primeiro princípio

Cada pessoa deve ter um direito igual ao mais abrangente sistema total de liberdades básicas iguais que seja compatível com um sistema similar de liberdades para todos.

Segundo princípio

As desigualdades econômicas e sociais devem ser dispostas de modo a que tanto:

(a) se estabeleçam para o máximo benefício possível dos menos favorecidos que seja compatível com as restrições do princípio de poupança justa, como (b) estejam vinculadas a cargos e posições abertos a todos em condições de igualdade equitativa de oportunidades (RAWLS, 2016, p. 376).

"Esses princípios devem ser dispostos em uma ordem serial, o primeiro sendo prioritário do segundo" (RAWLS, 2016, p. 74). Essa organização serial léxica significa que há uma complementariedade circular entre um direito e outro, o que confere a cada constituinte da ordem um peso, evitando, dessa forma, que se tornem mutuamente substituíveis. Desse modo, não há como um bem substituir o outro, ou seja, um não pode ser preterido em favorecimento ou para o exercício de outro.

Nesse sentido, Kymlicka destaca que, por meio desses princípios, Rawls admite que alguns bens sociais são mais importantes que outros e, desse modo, não podem ser sacrificados para melhorar outros bens. "As liberdades iguais têm prevalência sobre a igual oportunidade, que tem prevalência sobre os recursos iguais (KYMLICKA, 2006, p. 68). 


\section{JOHN RAWLS E AMARTYA SEN: PARALELO ENTRE A TEORIA DE JUSTIÇA COMO EQUIDADE E A JUSTIÇA FOCADA NAS REALIZAÇÕ}

Contudo, o autor segue destacando que dentro de cada categoria a ideia de Rawls prevalece, qual seja: "uma desigualdade só é permitida se beneficia os que se encontram em pior situação" (p. 68). Assim, essas regras da prioridade em nada afetam o princípio básico de parcelas equitativas.

A articulação de Rawls nos dois princípios reúne três componentes. O primeiro princípio abrange as liberdades e os direitos fundamentais que devem ser assegurado igualmente a todos e engloba os direitos liberais clássicos, tais como as liberdades de pensamento e associação e os direitos e liberdades essenciais à estrutura democrática. $\mathrm{O}$ segundo reúne elementos de igualdade equitativa de oportunidades que devem ser iguais para alcançar posições na sociedade àqueles que têm talentos similares; além de reunir elementos do princípio de diferença ou critério maximin de justiça social, para o qual somente deve-se admitir a desigualdade econômica que favorecer ao terço mais pobres da sociedade (VITA, 2016, p. XXIII-XXIV).

Ademais, em relação ao primeiro princípio, Freeman (2016, p. 61) esclarece:

A ideia primordial do primeiro princípio é que há certos direitos e liberdades básicos da pessoa que são más importantes que outros, e que são necessários para caracterizar o ideal moral das pessoas livres e iguais. Com o primeiro princípio Rawls pretende, primeiro, definir um ideal democrático de cidadãos livres que têm status cívico igual com poderes para influenciar equitativa e efetivamente na legislação e participar da vida política pública. (...). Segundo, o primeiro princípio na Teoria da Justiça é parte do ideal liberal de Rawls de pessoas livres e autônomas que desenvolvem suas capacidades humanas e configuram e seguem modos de vida que são intrinsecamente gratificantes. ${ }^{4}$

O Princípio da Diferença, por sua vez, trata da distribuição de renda e riqueza, e de cargos de autoridade e responsabilidade na sociedade, abarcando dois subprincípios, a saber: a igualdade equitativa de oportunidades e o princípio da diferença. Rawls aceita as desigualdades econômicas e sociais, ele sabe que elas vão sempre existir, mas desde que tragam maiores benefícios possíveis aos mais necessitados e desde que haja igualdade de oportunidades.

\footnotetext{
${ }^{4}$ No original: La ideia primordial del primer principio es que hay ciertos derechos y libertades básicas de la persona que son más importantes que otros, y que se necesitan para caracterizar el ideal moral de las personas libres e iguales. Com el primer principio Rawls pretende, primero, definir un ideal democrático de ciudadanos libres que tiene estatus cívico igual con poderes para influir equitativa y efetivamente em la legislación y participar en la vida política pública. (...). Segundo, el primer principio em Teoría de la justicia es parte del ideal liberal de Rawls de personas libres autónomas que desarrollan sus capacidades humanas y configuran y siguen modos de vida que son intrínsecamente gratificantes (FREEMAN, 2016, p. 61).
}

Rev. de Teorias da Justiça, da Decisão e da Argumentação Jurídica | e-ISSN: 2525-9644| Maranhão | v. 3 | n. 2 | p. 1 - 21| Jul/Dez. 2017. 
No que diz respeito à igualdade equitativa de oportunidades, tem-se que, por meio dela, devem ser garantidas oportunidades iguais de acesso aos cargos e a posições de autoridade na sociedade. Portanto, assim como o primeiro princípio, este subprincípio volta-se à igualdade de oportunidades. Sobre ela, Brito Filho (2015, p. 59) exorta:

O princípio da igualdade equitativa de oportunidades, que para Rawls não deve ser visto como conduzindo a uma sociedade meritocrática, tem como objetivo garantir que todos tenham acesso, de forma equitativa, aos cargos e posições disponíveis, e isso pode indicar que, em alguns casos, deverá a sociedade dar mais atenção aos que têm menos, em termos de talentos e de condições sociais e econômicas.

Por sua vez, o subprincípio da diferença admite distribuição desigual de renda e riqueza, desde que essa desigualdade seja benéfica para todos, especialmente aos mais necessitados ou menos favorecidos. É o que Brito Filho (2015, p. 59) chama de desigualdade controlada, para o qual

Ela teria, como teto, o que cada indivíduo licitamente amealhar, menos o que é destinado, especialmente pela tributação - e que pode ser progressiva -, à redistribuição, e como piso os Direitos Humanos e, no plano interno dos Estados, os Direitos Fundamentais, que podem ser representados, na teoria de Rawls, pelos bens primários, mais abaixo referidos.

O princípio da diferença é, então, direcionado primeiramente às instituições da estrutura básica da sociedade. É importante observar que esse princípio possui um papel importante na justiça como equidade, pois reúne tanto um princípio de reparação, segundo o qual tanto as igualdades como as desigualdades imerecidas devem ser reparadas, quanto uma concepção de reciprocidade, pois as arbitrariedades naturais e sociais só devem ser admitidas quando resultarem em benefício comum.

Por isso, Freeman (2016, p 106) conclui:

O princípio da diferença de Rawls não adiciona simplesmente um dever de justiça para assistir aos pobres através de uma lista tradicional de deveres que a sociedade tem em relação aos seus Membros. Não é apenas o dever de prestar "pagamentos de bem-estar" ou assistência pública a quem se encontra limitado por circunstâncias infelizes. O princípio da diferença é mais profundo do que isso e funciona em plano diferente. Ele deve se projetado desde o início, com base em perspectivas econômicas dos menos desfavorecidos, instituições legais que especifiquem direitos de propriedade e contrato, e instituições econômicas que tornem possível a produção, o comércio e o consumo. ${ }^{5}$

\footnotetext{
${ }^{5}$ No original: El principio de diferencia de Rawls no agrega simplemente un deber de justicia para assistir al pobre mediante una lista tradicional de deberes que la sociedad tiene para con sus membros. No se trata sólo del deber de proveer "pagos de bienestar" o asistencia pública a quienes se encuentran limitados por circunstancias
} 


\section{JOHN RAWLS E AMARTYA SEN: PARALELO ENTRE A TEORIA DE JUSTIÇA COMO EQUIDADE E A JUSTIÇA FOCADA NAS REALIZAÇÕES}

Segundo Rawls (2016, p.122), “a distribuição natural não é justa nem injusta; nem é injusto que se nasça em determinada posição social. Isso são meros fatos naturais. Justo ou injusto é o modo como as instituições lidam com esses fatos". Por isso, o princípio de diferença se refere às instituições. Portanto, fica claro que há em Rawls uma evidente preocupação com os menos favorecidos.

Por fim, no que diz respeito aos princípios da justiça, é importante destacar que há neles também uma preocupação com a justiça entre as gerações. Rawls (2016, p. 359) esclarece que, na posição original, as partes "devem concordar com um princípio de poupança que assegure que cada geração receba de seus predecessores o que lhe é devido e faça sua parte justa em favor daqueles que virão depois".

Pelo princípio da poupança justa, incluído no princípio da diferença, a redistribuição, que é feita, principalmente tendo em vista as necessidades dos menos favorecidos, que poderão usufruir dos bens primários, especialmente renda e riqueza, é limitada em razão de que uma parte do que seria redistribuído deve ser direcionado para formação de uma poupança em favor das gerações futuras. Assim, as gerações precedentes poupam para que as futuras possam gozar de um mínimo social a ser distribuído com base no princípio da diferença (BRITO FILHO, 2015, p. 67-68).

Desta análise dos princípios da justiça, há preocupações de Rawls que restam evidentes: em primeiro lugar, o autor preocupa-se com a igualdade formal no que diz respeito às liberdades fundamentais. Em segundo lugar, há uma forte preocupação com a igualdade material na distribuição de renda e riqueza e no acesso aos cargos e posições na sociedade, pois não basta às pessoas liberdade formal se a elas não forem concedidas condições de liberdade material. É dizer que dos princípios de justiça se extrai o nítido objetivo de proporcionar a todos, singularmente considerados, condições materiais necessárias para realização dos seus planos de vida, quaisquer que sejam eles.

No ideal de sociedade rawlsiano, o bem e o justo são compatíveis e é isso que torna o todo congruente. Rawls busca demonstrar que, "dadas as circunstâncias de uma sociedade

desafortunadas. El principio de diferencia es más profundo que eso y funciona en um plano diferente. Deben diseñarse desde el principio, con base em las perspectivas económicas de los menos favorecidos, instituiciones legales que especifiquen derechos de propriedad y contrato, e instituiciones económicas que hagan posible la producción, el comercio y el consumo (FREEMAN, 2016, p. 106).

Rev. de Teorias da Justiça, da Decisão e da Argumentação Jurídica | e-ISSN: 2525-9644| Maranhão | v. 3 | n. 2 | p. 1 - 21| Jul/Dez. 2017. 
bem-ordenada, o plano de vida racional de uma pessoa sustenta e afirma seu senso de justiça" (2016, p.633), bem como "um senso de justiça efetivo pertence ao bem da pessoa e, assim, as tendências à instabilidade são mantidas sob controle, se é que não são eliminadas" (RAWLS, 2016, p. 633).

Nesse contexto, três aspectos devem ser verdadeiros: primeiro o desenho de sociedade bem ordenada traçado por ele favorece a autonomia de seus membros e seus juízos de direito e justiça. Depois, o ideal de justiça combina com o ideal de sociedade onde vigora a união entre seus membros, pois os laços afetivos diminuem os efeitos danosos da inveja e do ressentimento e definem um equilíbrio onde a liberdade de realizar seu plano de vida é prioritário. E, por fim, as instituições justas proporcionam o que ele chama de "unidade do eu", proporcionando condições aos indivíduos de desenvolverem suas potencialidades.

A ideia de sociedade justa exposta na obra de Rawls indica uma preocupação que transcende os interesses individuais. Em seu projeto de sociedade bem ordenada e justa, os indivíduos são vistos como cidadãos iguais, ou seja, todos têm valor intrínseco e, em razão disso, todos possuem importância para a sociedade e o Estado justo não pode impor aos indivíduos uma única ideia de bem. Assim, a cada um é dada liberdade para perseguir seu plano de vida conforme suas próprias convicções de bem e ideia de vida boa, cabendo, contudo, ao Estado a garantia do mínimo necessário para perquirição de qualquer projeto de vida, ou seja, os bens básicos.

De posse de bens indispensáveis, o indivíduo poderá usar da racionalidade deliberativa e escolher qual caminho trilhar, pois há muitos caminhos a seguir, considerando que o ser humano é de uma variedade infinita em seus talentos e inteligência. A atuação do Estado, com base em uma ideia de justiça, inicia e se esgota na distribuição de bens fundamentais.

Apresentada a teoria rawlsiana, passa-se, então, na próxima seção, à análise da abordagem da igualdade de capacidades de Sen.

\section{A IGUALDADE DE CAPACIDADES DE SEN}

As ideias igualitárias de Sen partem da pergunta: igualdade de quê? O autor coloca em pauta o local correto em que deve ser buscada a igualdade, pois as distintas teorias colocam a igualdade em algum espaço o que "pode fazer com que se seja anti-igualitário em algum outro espaço, cuja importância comparativa na avaliação global tem de ser apreciada 


\section{JOHN RAWLS E AMARTYA SEN: PARALELO ENTRE A TEORIA DE JUSTIÇA COMO EQUIDADE E A JUSTIÇA FOCADA NAS REALIZAÇÕES}

criticamente" (SEN, 2012, p. 47). Desse modo, as várias teorias igualitárias podem ser distinguidas em relação ao espaço em que cada uma delas entende que as pessoas podem ser iguais, o que Sen chama de igualdade basal.

Rawls (2016, p.75-76), como dito, coloca no centro de sua teoria a distribuição igualitária de bens sociais primários compreendidos de forma ampla pela liberdade, oportunidade e riqueza, bens que todo indivíduo racional deseja, não importando o que mais deseje para a realização do seu plano de vida. Estes bens são distribuídos pelas instituições sociais.

Sen (2012, p. 34), por seu turno, defende a igualdade de capacidades, entendendo a capacidade como o que concede conteúdo à liberdade. Em outras palavras, as capacidades são as possibilidades de transformar bens primários sociais, tendo em vista os funcionamentos dos indivíduos. A ideia de capacidades está atrelada, portanto, à igualdade de oportunidades e, assim, à liberdade de escolha para alcançar seus objetivos. Seu interesse está relacionado à necessidade de desenvolver uma teoria que não se "limite à escolha das instituições nem à identificação de arranjos sociais ideais" (SEN, 2011, p. 48). Em seu ponto de vista, “a necessidade de uma compreensão da justiça que seja baseada na realização está relacionada ao argumento de que a justiça não pode ser indiferente às vidas que as pessoas podem viver de fato" (SEN, 2011, p.48).

Isso não quer dizer que Sen não reconheça a importância das instituições e das regras na realização de um projeto de justiça social. Mas considera que as realizações de fato não se limitam ao quadro organizacional, pois incluem as vidas que as pessoas de fato conseguem viver. Logo, a liberdade das pessoas está relacionada à possibilidade de escolha entre diferentes tipos de vida.

Desse modo, tanto a teoria de Sen, quanto a de Rawls, almejam a meta correta, que é a liberdade para realizar, e não a realização propriamente dita, mas percorrem caminhos diferentes. A problemática, segundo Sen (2012, p. 50), é que os "seres humanos diferem uns dos outros de muitos modos distintos". Logo, essa variedade transforma a relação entre renda e bem-estar, tornando-a muito variável de acordo com as possibilidades que cada pessoa possui para transformar renda em bem-estar. Bens primários, para Sen, são meios para a liberdade, que podem ou não converterem-se em liberdade a depender da capacidade de cada pessoa. Por isso, não basta que as pessoas sejam igualadas na renda, "a liberdade tem de ser

Rev. de Teorias da Justiça, da Decisão e da Argumentação Jurídica | e-ISSN: 2525-9644| Maranhão | v. 3 | n. 2 | p. 1 - 21| 
distinguida não apenas da realização, mas também de recursos e meios para a liberdade" (SEN, 2012, p. 75).

Nesse contexto, a abordagem das capacidades traduz-se em uma estrutura para a avaliação do bem-estar do indivíduo e da liberdade para que esse bem-estar seja buscado. Desse modo, situações tais como a pobreza, as desigualdades e as políticas públicas podem ser analisadas a partir dos conceitos de funcionamentos (functionings) e capacidades (Capability Approach) ${ }^{6}$. Os funcionamentos, por sua vez, são aquilo que uma pessoa pode considerar valioso fazer ou ter, podendo ser elementares ou complexos e serão sempre constitutivos para o bem-estar individual. Sen (2012, p. 95) explica:

\begin{abstract}
A realização de uma pessoa pode ser concebida, sob esse aspecto, como o vetor de seus funcionamentos. Os funcionamentos relevantes podem variar desde coisas elementares como estar nutrido adequadamente, estar em boa saúde, livre de doenças que podem ser evitadas e da morte prematura etc., até realizações mais complexas, tais como ser feliz, ter respeito próprio, tomar parte na vida da comunidade, e assim por diante. A asserção é de que os funcionamentos são constitutivos do "estado" [being] de uma pessoa, e uma avaliação do bem-estar tem de assumir a forma de uma apreciação desses elementos constituintes.
\end{abstract}

Assim, seria possível analisar, no contexto das políticas públicas, o bem-estar de uma pessoa em termos da qualidade de seu estado e se sua vida está intimamente ligada ao conjunto de funcionamentos, que compreendem estados e ações, todos inter-relacionados, que desencadeia ao longo da vida.

Os funcionamentos são os elementos constitutivos do bem-estar individual, e a capacidade está atrelada à possibilidade de realizar funcionamentos. Sen interliga a ideia de liberdade à capacidade de produzir funcionamentos. Assim, nas palavras de Lamarão Neto e Brito Filho (2016, p. 91), "considera que a liberdade pode ser vista como intrinsecamente importante para uma boa estrutura social. Uma boa sociedade também é, nesta concepção, uma sociedade de liberdade".

Desse modo, resta evidente que Sen instaura uma nova forma de se pensar a distribuição de bens em uma sociedade. Embora sua abordagem possua semelhança com a igualdade de bens primários de Rawls, em detrimento da igualdade de bem-estar, o autor propõe algo a mais, pois para ele não basta igualar as pessoas em renda e riquezas, é preciso

\footnotetext{
6 A expressão "Capability Approach" é frequentemente traduzida para o português como "abordagem das capacidades". Contudo, os tradutores das obras de Sen optam pela tradução dos termos "capability" e "functionings" respectivamente por "capacidade" e "funcionamentos".
} 


\section{JOHN RAWLS E AMARTYA SEN: PARALELO ENTRE A TEORIA DE JUSTIÇA COMO EQUIDADE E A JUSTIÇA FOCADA NAS REALIZAÇÕES}

que as pessoas sejam iguais na capacidade de transformar essa renda e riqueza em capacidade real de realizações, uma vez que o autor considera a enorme diversidade entre as pessoas.

Para que fique claro, andar de bicicleta, por exemplo, pode ser considerada uma espécie de funcionamento. A bicicleta é um instrumento e é preciso compreender qual razão leva distintas pessoas a usarem este instrumento. Um rico executivo com forte consciência ecológica decide ir ao trabalho todos os dias de bicicleta e um pobre homem também vai de bicicleta todos os dias à fábrica onde trabalha. Ambos estão compartilhando do mesmo funcionamento (functioning), mas por razões muito distintas. O rico executivo fez a opção de ir de bicicleta, mas poderia ir de carro particular ou de táxi. Por sua vez, o operário vai de bicicleta porque não tem outra opção. Desse modo, fica claro que o executivo possui maior liberdade que o trabalhador, uma vez que pode escolher entre um leque de opções disponíveis (REGO; PINZANI, 2014, p. 68).

Nessa esteira de raciocínio, algumas questões sociais relevantes podem ser consideradas. É diferente quando alguém passa fome porque está de dieta, ou porque está fazendo jejum de quando uma pessoa passa fome porque não possui dinheiro e nem meios para adquirir comida. Ou mesmo é diferente quando alguém não faz determinado tratamento por não acreditar na sua eficácia e quando alguém não faz esse mesmo tratamento porque não tem condições de custear os fármacos indicados.

Fica claro, então, que a proposta de Sen não visa igualar as pessoas em seus funcionamentos, uma vez que os funcionamentos "são constitutivos do bem-estar, a capacidade representa a liberdade de uma pessoa para realizar bem-estar" (SEN, 2012, p. 89). Ou seja, a proposta de Sen é tornar as pessoas livres para escolher os funcionamentos que para elas são relevantes, e o que deve ser buscado é a igualdade de capacidades para realizar estes funcionamentos, ou seja, a igualdade de liberdade para realizar. Na visão de Gargarella (2008, p. 72-73), segundo Sen, “o que deveria ser considerado é algo 'posterior' à posse desses recursos, mas 'anterior' à obtenção da utilidade".

Assim, fica evidente a preocupação de Sen com as circunstâncias pessoais dos indivíduos. Diante da diversidade humana ele considera a pessoa como um todo, o que come, onde vive, onde trabalha, em qual cultura está inserida, dentre outros inúmeros fatores. $\mathrm{O}$ autor sabe que as pessoas não possuem os mesmos talentos e nem as mesmas capacidades;

Rev. de Teorias da Justiça, da Decisão e da Argumentação Jurídica | e-ISSN: 2525-9644| Maranhão | v. 3 | n. 2 | p. 1 - 21| 
preocupa-se com as possibilidades reais que as pessoas têm de empregar seus recursos nos seus próprios objetivos para a obtenção dos mesmos graus de realizações. Nesse sentido:

as capabilities se referem não somente a capacidades e habilidades, mas também a estados mentais, a outros estados subjetivos (como estar com saúde, ser alfabetizado etc.) e circunstancias externas. Portanto, podem ser pensadas somente como um conjunto, e não como qualidades isoladas (REGO; PINZANI, 2014, p. 69).

Sen considera que a liberdade tem um significado negativo de ausência de interferência do Estado na esfera privada, mas afirma que a liberdade está relacionada à expansão das capacidades, ou seja, à ampliação das possibilidades de escolha que as pessoas podem ter para levarem a vida que valorizam (SEN, 2010, p. 32).

Em resumo, a concepção de justiça de Sen está relacionada às particularidades de cada pessoa, assim como às privações pelas quais passam. Ao considerar que a teoria centrada nas realizações é o modelo adequado de justiça social compreende que as liberdades substanciais podem ser ampliadas. A ideia de liberdade, assim, não pode ser dissociada da realização da igualdade no seu sentido material, o que relaciona aos direitos sociais como prioritários para proporcionar a igualdade de capacidades, pois a privação desses direitos afeta diretamente a capacidade de escolha e autonomia das pessoas.

Traçado um paralelo entre as teorias, o próximo tópico cuida de destacar propriamente as críticas de Sen a Rawls.

\section{AS CRÍTICAS DE AMARTYA SEN}

Embora Sen deixe claro o tamanho de sua admiração por Rawls em diversas passagens ao longo da sua obra, o autor não se furta de elaborar as críticas que entende pertinentes à produção rawlsiana, a maioria delas presentes na parte I da obra A ideia de justiça do autor.

Porém, da análise das obras de Sen, percebe-se que ele vem dialogando com a teoria da justiça de Rawls desde muito antes da publicação da obra A ideia de Justiça. Assim, o presente tópico não tem a pretensão de esgotar o assunto tratando de toda complexidade do debate, mas apenas objetiva apontar a relação que Sen faz da sua própria teoria com a de Rawls e em que medida pretende que suas ideias sejam um avanço à proposta rawlsiana.

Sen, em diálogo com a teoria de Rawls, propõe um enfoque que, para o autor, seria mais apropriado para lidar com as desigualdades provenientes de diversas formas de 


\section{JOHN RAWLS E AMARTYA SEN: PARALELO ENTRE A TEORIA DE JUSTIÇA COMO EQUIDADE E A JUSTIÇA FOCADA NAS REALIZAÇÕES}

contingências sociais, variações que resultam em diferentes maneiras de conversão da renda e da riqueza que os indivíduos possuem em formas de vida distintas, na vida que cada pessoa pode levar.

Nesse sentido, a primeira consideração de Sen diz respeito à métrica rawlsiana de escolha única, na posição original, de determinado conjunto de princípios para as instituições justas necessárias para uma sociedade plenamente justa. Como dito alhures, Sen ressalta que Rawls faz parte dos autores de linhagem institucionalista, aqueles que centram suas teorias de justiça distributiva em uma tentativa de acertar as instituições, sem focalizar diretamente nas sociedades reais. Contudo, para Sen (2011, p.87):

Há interesses gerais genuinamente plurais, e às vezes conflitantes, que afetam nossa compreensão de justiça. Eles não precisam diferir de maneira conveniente - ou seja, conveniente para a escolha -, de forma que só um conjunto de princípios realmente incorpore a imparcialidade e a equidade, enquanto os outros não.

O autor considera que, mesmo diante de condições ideais, não é possível administrar uma teoria da justiça focada apenas, ou principalmente, nas instituições justas geridas por determinados princípios, isso porque há uma pluralidade de concepções de justiça que não seriam abrangidas por um único conjunto de princípios escolhidos. E, para Sen, "a imparcialidade pode assumir muitas formas diferentes e ter manifestações bastante distintas" (2011, p. 87).

Desse modo, Sen destaca que diante de uma pluralidade de princípios relacionados a avaliação da justiça não é possível que um único conjunto de princípios seja escolhido. Nessa linha de argumentação, Sen apresenta o exemplo de três crianças que reivindicam uma flauta. Anne deseja o objeto, pois é a única que sabe tocá-lo; por sua vez, Bob é o mais pobre entre os três e por isso reivindica a flauta; por fim, Carla alega que foi ela mesma quem produziu o objeto, portanto ele deve ser seu. A partir desse exemplo é possível que se invoque diferentes concepções de justiça, tais como o utilitarismo, igualitarismo econômico, libertarismo, sendo que todas elas poderia ofertar uma solução para a problemática de quem deveria ficar com a flauta, sustentando ser a decisão mais correta.

Assim, nesse exemplo, podem ser detectados três argumentos diferentes em relação às pretensões da justiça, a saber: a busca da satisfação humana, a eliminação da pobreza, e, ainda, o direito de obter os frutos do próprio trabalho. A grande questão que se impõe é que

Rev. de Teorias da Justiça, da Decisão e da Argumentação Jurídica | e-ISSN: 2525-9644| Maranhão | v. 3 | n. 2 | p. 1 - 21| 
cada um desses argumentos indicam uma solução diferente, mas todas a partir de razões imparciais e não arbitrárias.

A segunda crítica de Sen diz respeito à prioridade da liberdade formal rawlsiana. Nesse sentido, é sabido que os princípios de justiça de Rawls incluem a prioridade da liberdade, atribuindo precedência à liberdade máxima para cada pessoa sujeita à liberdade semelhante para todos, em relação a outras considerações, incluindo as de equidade econômica ou social. "Ou seja, as liberdades que todos podem desfrutar não podem ser violadas em razão, digamos, da promoção da riqueza ou renda, ou para uma melhor distribuição de recursos econômicos entre as pessoas" (SEN, 2011, p. 90).

Nesse contexto, a crítica de Sen é a crítica ao extremismo considerado por ele presente na teoria de Rawls. Sen reconhece que as liberdades formais desempenham um papel importante para os indivíduos na sociedade, mas considera que o reconhecimento dessas liberdades não pode se dar de modo a fazer com que as necessidades outras sejam desconsideradas. Por isso, questiona: "Por que deveríamos considerar a fome coletiva, a fome individual e a negligência médica invariavelmente menos importantes do que a violação de qualquer tipo de liberdade pessoal?" (SEN, 2011, p.96).

A terceira e talvez a mais extensa crítica de Sen diz respeito à métrica dos bens primários, pois, como dito, Rawls utiliza os bens primários (direitos, liberdades, oportunidades, riqueza, renda e as bases sociais do autorrespeito) como a base de sua proposta de justiça distributiva. Porém, Sen considera que a métrica dos bens primários não leva em consideração variações que as pessoas apresentam quanto às capacidades de converter bens primários em viver bem e propõe a mudança de foco dos bens primários para a avaliação real das liberdades e capacidades (cf. SEN, 2000, p. 91-94; SEN, 2011, p. 96/97).

Para Sen, os bens primários são recursos utilizados para satisfação das necessidades dos indivíduos. Acontece que o uso desses recursos para fazer coisas que sejam valiosas ao indivíduo está sujeito a um conjunto de variáveis, tais como as características de cada pessoa, o local onde vivem, as circunstâncias climáticas, a renda, dentre outros. Logo, se os meios e os contextos são diferentes, também será diferente a capacidade que cada pessoa terá para transformar esse quinhão de bens naquilo que é valioso para si.

Sobre isso Vita $(1999$, IV) resume:

Se os arranjos institucionais distribuem um quinhão equitativo de bens primários a todos, podemos ignorar, para as finalidades da justiça social, os interesses diversos que se definem a partir das aspirações, concepções do 
bem e necessidades individuais. Duas pessoas às quais são proporcionadas parcelas iguais desses bens, podem emprega-las em objetivos muito diferentes. Uma delas pode valorizar o êxito em uma carreira profissional que requer empenho continuado, disposição para competir e sacrifício do tempo de lazer. A outra prefere uma carreira profissional que exige menos dedicação e que, em contrapartida, lhe deixa mais tempo livre para se dedicar à família ou ao auto-aperfeiçoamento.

Desse modo, na proposta de Sen, uma teoria de justiça igualitária não deve se pautar na igualdade de bens primários, pois segundo o autor "o que deveria ser considerado é algo "posterior" à posse desses recursos, mas "anterior" à obtenção da utilidade, como pode ser, por exemplo, o nível nutricional de cada um” (GARGARELLA, 2008, p. 72-73). Isso porque a igualdade tanto almejada só ocorrerá a partir da avaliação das capacidades de cada indivíduo para converter os recursos em liberdades para realizar.

Isso não quer dizer que Sen descarte por completo o modo de Rawls compreender as liberdades, mas faz a defesa de uma visão mais ampla, uma liberdade mais abrangente para realizar, o que não descaracteriza o significado da liberdade negativa, apenas acrescenta a ele a necessidade de proporcionar às pessoas condições de liberdades materiais a partir das suas diversidades pessoais e recursos para a transformação em capacidades.

O lugar no qual essas críticas se encontram está, então, para Sen, na insuficiência da teoria de justiça de Rawls quando se concentra em um ideal de justiça ou de instituições justas, sem, contudo, analisar a aplicação prática desse ideal nas sociedades e instituições reais. É a partir desse enfoque que Sen elabora sua concepção de justiça social, com base nas teorias da escolha social (CONSANI, 2016).

\section{CONSIDERAÇÕES FINAIS}

Apresentadas as teorias, de um lado a justiça como equidade de John Rawls e de outro a abordagem das capacidades de Amartya Sem; assim como analisadas as críticas formuladas por Sen à abordagem rawlsiana, é possível concluir que, apesar das divergências, são muitos os pontos de contato, pois ambas as teorias se dedicam à elaboração de concepções de justiça de abordagem igualitarista e procuram soluções para as desigualdades nas sociedades democráticas contemporâneas. Portando, quando analisadas em conjunto, apresentam-se de considerável relevância em uma sociedade tão desigual e plural como a que se vive.

Rev. de Teorias da Justiça, da Decisão e da Argumentação Jurídica | e-ISSN: 2525-9644| Maranhão | v. 3 | n. 2 | p. 1 - 21| Jul/Dez. 2017. 
A abordagem de Sen, focada nas capacidades, ou seja, focada nos fins e não nos meios, pode vir a lidar melhor com as situações de diferenças presentes nas sociedades, tanto as diferenças individuais, tais como as doenças, as deficiências físicas, relativas às variações individuais de funcionamentos, quanto as diferenças de contextos econômicos. Em tese, tratar-se-ia de uma abordagem mais sensível à diferença entre as pessoas. Logo, sendo as pessoas diferentes nesses variados aspectos, por óbvio há casos de indivíduos que precisam de maiores quantidades de recursos para satisfação de necessidades que outros necessitariam em menor quantidade. Logo, nessa abordagem, os bens primários apresentam-se como limitados diante de todas as variedades perceptíveis.

Rawls, por sua vez, almeja igualar as pessoas nas mesmas liberdades, mesmos direitos, mesma igualdade, mesmos bens materiais, e o mesmo autorrespeito. Diante da diversidade humana, os bens primários são o substrato imprescindível para a realização de qualquer plano de vida. Mas, Sen acredita que isso é só um meio, deseja igualar as pessoas na liberdade para ser, fazer e viver em funcionamento. Para Sen as pessoas só são iguais nos direitos e liberdades se a uma forem proporcionadas condições iguais que à outra, logo, nesse contexto, é imprescindível que às pessoas seja proporcionado todo o necessário para que cheguem a um ponto igual.

Da forma que foi exposta, e analisada isoladamente, a teoria de Sen retrata a última fronteira da diversidade humana, expõe a necessidade de conceder a cada indivíduo um conjunto amplo de condições, tudo que necessita para realização de todos os seus planos de vida, correndo, assim, o risco de ser irrealizável.

Ademais, cabe o questionamento em relação a que medida uma teoria da justiça pode abdicar de um modelo ideal de justiça ou de sociedade justa a partir das instituições que dela fazem parte. Pois, sem esse ideal, a proposta de Sen corre outro risco, o de não avançar rumo à eliminação das injustiças, pois, embora a análise global das injustiças realizada por Sen seja relevante, é inevitável reconhecer que é no âmbito de cada Estado e por meio de suas instituições sociais que os direitos básicos dos indivíduos lhes são assegurados.

Em suma, Sen dá indícios de reconhecer a possibilidade de que teorias da justiça contratualistas e de cunho transcendental sejam complementadas por teorias da escolha social. Desse modo, a crítica formulada por Sen não rejeita em absoluto a teoria de Rawls, mas sim pretende somar à ela elementos considerados importantes e ausentes pelo autor, de modo a 
torná-la mais realizável nas sociedades. Portanto, na busca da redução das injustiças, abordagem significativa é a que utiliza-se de Sen em complementariedade à Rawls.

\section{REFERÊNCIAS}

BRITO FILHO, José Claudio Monteiro de. Direitos Humanos. São Paulo: LTr, 2015.

CONSANI, Cristina Foroni. Justiça como equidade ou justiça focada em realizações? As concepções de justiça de John Rawls e de Amartya Sen. Saberes, Natal, RN, v. 1, n. 13, p. 76-96, $2016 . \quad$ Mar., Disponível em: <https://periodicos.ufrn.br/saberes/article/download/8404/6310>. Acesso em: 06 jul. 2017.

FREEMAN, Samuel. Rawls. Traducción Adolfo García de la Sienra. México: FCE, 2016 (Colec. Sección de Obras de Filosofia).

GARGARELLA, Roberto. As teorias da justiça depois de Rawls: um breve manual de filosofia política. Trad. Alonso Reis Freire. São Paulo: WMF Martins Fontes, 2008. p. 1-31.

LAMARÃO NETO, Homero; BRITO FILHO, José Claudio Monteiro de. Igual consideração e a incidência das variáveis políticas em Dworkin e Sen. In: ROBL FILHO, Ilton Norberto e TRAMONTINA, Robison (Org.). XXV Encontro Nacional do CONPEDI BRASÍLIA/DF: Teorias da Justiça, da decisão e da argumentação jurídica. Florianópolis: CONPEDI, 2016, p. 79-94. Disponível em: < http://www.conpedi.org.br/publicacoes/y0ii48h0/4lq86vdx/97ope1EKfLO6JdKn.pdf $>$. Acesso em 09 mar. 2017.

LOVETT, Frank. Uma teoria da Justiça, de John Rawls Guia de Leitura. Trad. Vinicius Figueira. Porto Alegre: Penso, 2013. (Col. Explorando Grandes Obras).

RAWLS, John. Uma teoria da justiça. 4 ed.rev. Tradução de Jussara Simões. São Paulo: Martins Fontes, 2016.

REGO, Walquiria Leão; PINZANI, Alessandro. Vozes do bolsa família. São Paulo: Unesp, 2013.

SEN, Amartya. Desenvolvimento como liberdade. Tradução de Laura Teixeira Motta. 4 reimpressão. São Paulo: Companhia das Letras, 2010.

A ideia de justiça. Tradução de Denise Bottmann e Ricardo Doninelli Mendes. 3 reimpressão. São Paulo: Companhia das Letras, 2011.

Desigualdade reexaminada. Tradução de Ricardo Doninelli Mendes. Rio de Janeiro: Record, 2012.

VITA, Álvaro de. “Apresentação da Edição Brasileira”. In: RAWLS, John. Uma Teoria da Justiça. 4 ed.rev. Tradução de Jussara Simões. São Paulo: Martins Fontes, 2016.

- Justiça Distributiva: a Crítica de Sen a Rawls. Scielo Brasil, Rio de

Janeiro, v. 42, n. 3, p. 1-10, jan., 1999. Disponível em: http://www.scielo.br/scielo.php?script=sci_arttext\&pid=S0011-52581999000300004>.

Acesso em: 13 abr. 2017.

KYMLICKA, Will. Filosofia política contemporânea: uma introdução. Tradução de Luís Carlos Borges. São Paulo: Martins Fontes, 2006. 